\title{
High-Temperature Oxidation Behaviour of Co-Re-Cr-based Alloys: Limitations and Ways to Improve Bronislava Gorr ${ }^{1, a}$ and Hans-Jürgen Christ ${ }^{1, b}$
}

\author{
${ }^{1}$ Institut für Werkstofftechnik, Universität Siegen, Paul-Bonatz-Str. 9-11, 57068 Siegen, Germany \\ agorr@ifwt.mb.uni-siegen.de, bchrist@ifwt.mb.uni-siegen.de
}

Key words: Co-Re alloys, high-temperature oxidation, Re-oxide

\begin{abstract}
Ni-based alloys are the most widely used alloy system in high-temperature applications. However, the use of Ni-based alloys is limited to temperatures below $1100^{\circ} \mathrm{C}$. The experimental $\mathrm{Co}-\mathrm{Re}-\mathrm{Cr}$-based alloys are promising for high-temperature applications for service temperatures beyond $1200^{\circ} \mathrm{C}$. A complete miscibility in the Co-Re system allows to steadily elevate the melting point of the system with the rhenium content. In addition, rhenium takes the role as solid solution strengthening element. In the case of Co-based alloys, the oxidation resistance at high temperature is mainly based on the formation of a protective $\mathrm{Cr}_{2} \mathrm{O}_{3}$ scale. The purpose of the present investigations is to gain an insight into the oxidation mechanisms of the model Co-Re-Cr alloys and to find ways to improve oxidation resistance of this class of materials. Earlier investigations of the authors showed a rather poor oxidation resistance during exposure to laboratory air. Oxidation at $1000^{\circ} \mathrm{C}$ in air yielded an oxide scale that consists of a Co-oxide outer layer on a thick and porous $\mathrm{Co}-\mathrm{Cr}$ oxide and a semicontinuous and therefore non-protective $\mathrm{Cr}$-oxide film on the base metal substrate. As a consequence of the lacking protectiveness of the oxide layer the vaporization of rhenium oxide takes place and hence leads to a rapid loss of Re. The aim of recent investigations is to study the effect of $\mathrm{Si}$ on the high-temperature oxidation behaviour of Co-Re-Cr alloys by means of kinetic and microstructural examinations. It was found that $\mathrm{Si}$ stabilizes the $\mathrm{Cr}_{2} \mathrm{O}_{3} \quad \mathrm{scale}$, enhancing the oxidation resistance significantly. Hence, the synergetic effect of chromium with silicon could be considered as an encouraging perspective to improve the oxidation resistance of Co-Re-Cr alloys. Apart from that, other concepts to enhance the oxidation resistance of this class of materials are discussed, such as the formation of a borosilicate layer or protective $\mathrm{Al}_{2} \mathrm{O}_{3} \mathrm{scale}$ on the substrate surface.
\end{abstract}

\section{Introduction}

The constant push for higher-efficiency and lower-cost industrial processes typically involves higher temperatures and more aggressive environments. By improving the efficiency, less $\mathrm{CO}_{2}$ would be produced per kWh of electricity generated and the "extra" power can help offset the losses from the processes needed to reduce emissions or sequester the reaction products [1]. At present, Ni-based alloys are wedely used as high-temperature and high-strength materials in corrosive atmosphere [2]. However, the use of Ni-based alloys is increasingly restricted if temperatures exceed $1000^{\circ} \mathrm{C}$. Thus, as applications move to higher temperatures, new alloys are needed. The experimental Co-Re-based alloys were developed for high-temperature applications at service temperatures beyond $1200^{\circ} \mathrm{C}$.

High-temperature alloys are usually designed to a form protective oxide scale to resist oxidation. For long-term applications of an alloy at high-temperature, $\mathrm{Cr}_{2} \mathrm{O}_{3}, \mathrm{SiO}_{2}$, and $\mathrm{Al}_{2} \mathrm{O}_{3}$ are the main oxides considered for oxidation protection. The majority of commercially available hightemperature alloys form a chromia scale. For this reason, chromium was added to the base Co-Resystem to provide reliable protection against oxidation and environmental attack at intermediate temperatures (below $1000^{\circ} \mathrm{C}$ ). It should be noted that protective properties of $\mathrm{Cr}_{2} \mathrm{O}_{3}$ are increasingly reduced at temperatures above $1000^{\circ} \mathrm{C}$ and high flow rates of gas in oxidizing atmospheres, because of the accelerated transformation of $\mathrm{Cr}_{2} \mathrm{O}_{3}$ to volatile $\mathrm{CrO}_{3}$ [3]. Consequently, chromium alone will not provide sufficient oxidation protection at very high temperatures. Alloying additions of silicon and aluminium in the most alloys used for very high temperature are based on the slow rate at which their oxides grow and the fact that these oxides are considerably more stable than those of iron, nickel, and cobalt [4]. In comparison to chromia, $\mathrm{SiO}_{2}$ and $\mathrm{Al}_{2} \mathrm{O}_{3}$ sustain their protective properties also at the temperatures beyond $1000^{\circ} \mathrm{C}$. Thus, in addition to chromium, aluminium and silicon in the newly developed Co-Re alloys are favoured in order to provide protective oxide scales. 
The overall purpose of this paper is to review the oxidation performance of Co-Re model alloys and to provide a guideline for further alloy development regarding the improvement of the oxidation resistance of this class of materials.

\section{Material and Experimental Procedure}

Nine Co-based model alloys were investigated in this study. The chemical composition of these model alloys is shown in Fig. 1.

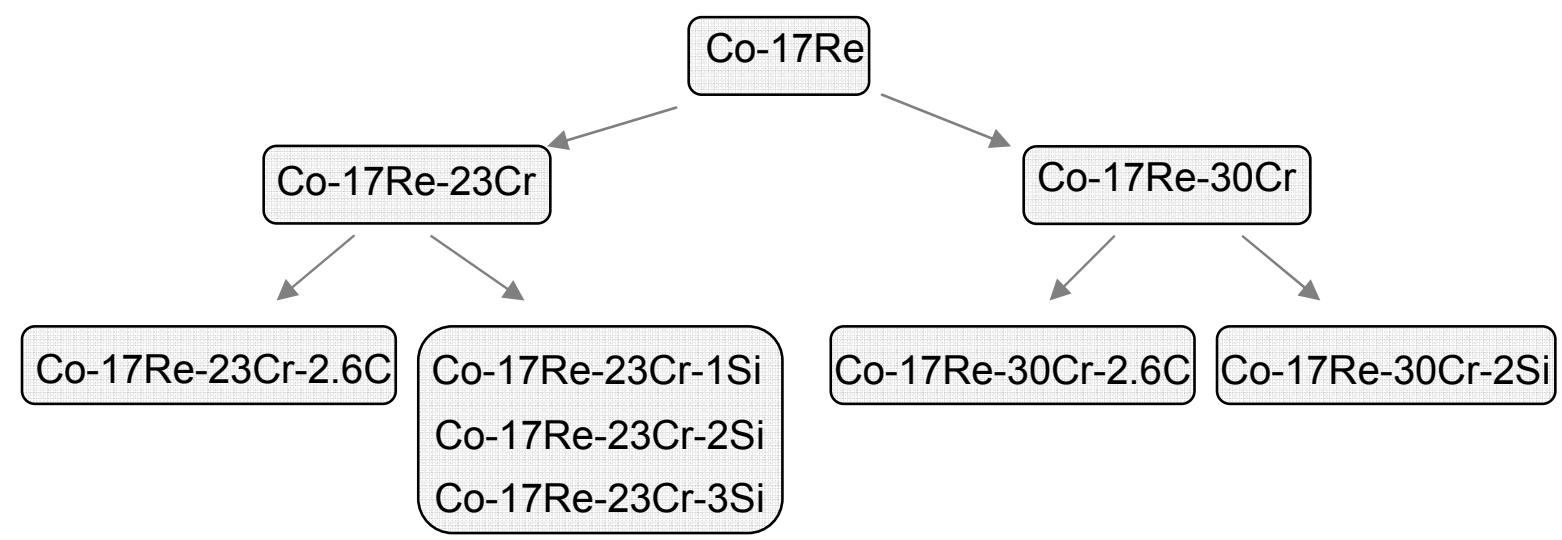

Fig. 1 - Chemical composition (in at.\%) of the model Co-Re alloys studied

Samples with a dimension of 10x10x $2 \mathrm{~mm}^{3}$ with rounded edges to avoid the typical edge effect on oxidation were used for the thermogravimetric study. The samples were ground using SiC paper down to 1200 grit and were cleaned ultrasonically in ethanol prior to oxidation. A hole of $1 \mathrm{~mm}$ diameter was drilled for hanging the samples using a Pt wire suspension. The surface area of each specimen was measured, in order to relate the mass change to this initial surface area. For the discontinuous thermogravimetric studies, the specimens were weighed together with the Pt wire and the self-designed alumina crucible. The purpose of the crucible was to collect all spalled corrosion products. After the oxidation, the crucibles with the specimens were weighed using a balance with high accuracy $\left(10^{-5} \mathrm{~g}\right)$. The continuous isothermal oxidation tests were carried out using a Sartorius microbalance of resolution of $10^{-6} \mathrm{~g}$ in combination with an alumina tube as reaction chamber surrounded by a $\mathrm{SiC}$ furnace. The oxidised samples were embedded in epoxy, ground and polished using diamond paste down to $1 \mu \mathrm{m}$ as the last step of preparation. The morphology and composition of the oxide scales were analysed using a scanning electron microscopy (SEM) in combination with energy-dispersive X-ray spectroscopy. X-ray diffraction (XRD) was used for phase identification.

\section{Results}

Figure 2 shows the mass change of the samples from different alloys after 72 hours of exposure at $1000^{\circ} \mathrm{C}$. Mass loss was detected for all alloys containing Re due to evaporation of rhenium oxide(s). The binary alloy Co-17Re shows the highest mass loss (Fig.2). The addition of $23 \% \mathrm{Cr}$ to the binary alloy Co-17Re improves the oxidation resistance significantly. An increase of the $\mathrm{Cr}$ content in the ternary alloy $\mathrm{Co}-17 \mathrm{Re}-\mathrm{Cr}$ from 23 at. $\%$ to $30 \mathrm{at} . \%$ seems to decrease the vaporization rate of rhenium oxide(s) further. An addition of $\mathrm{C}$ to the both ternary alloys $\mathrm{Co}-17 \mathrm{Re}-\mathrm{xCr}$ did not appreciably influence the oxidation behaviour (see Fig. 2). 


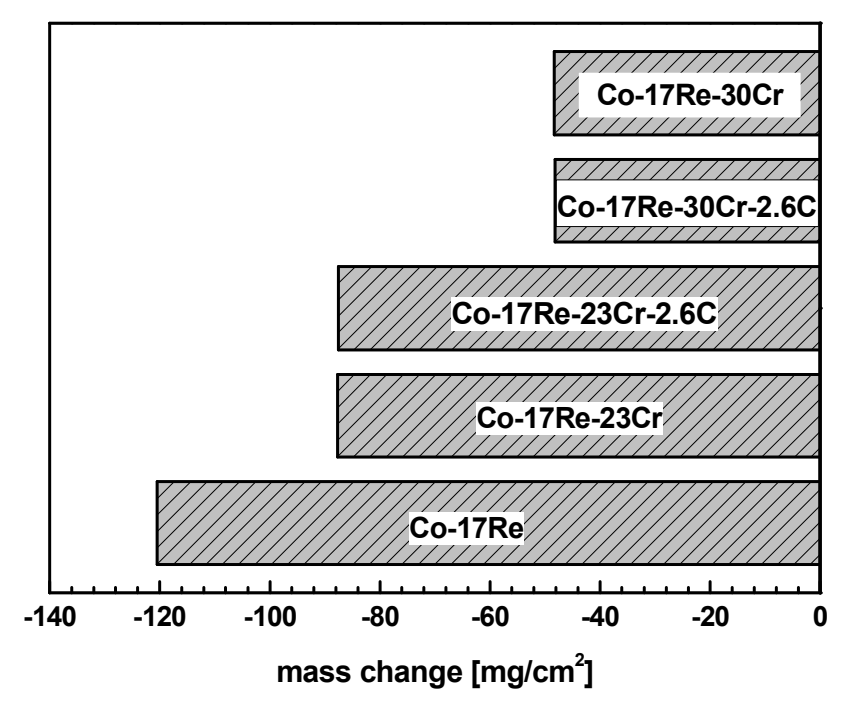

Fig. 2 - Mass change during oxidation in laboratory air after 72 hours at $1000^{\circ} \mathrm{C}$

In the binary alloy Co-17Re, the cobalt oxide scale comprises of two layers distinguished by the growth mechanisms that have been proposed by Kim and Hobbs [5]: (i) an outer layer with a coarse-grained columnar structure (Fig. 3), which is typical of a scale growing by outward diffusion of cations (Co) to the oxide/atmosphere interface, and (ii) an inner layer consisting of equiaxial grains typical of a scale growing by inward diffusion of oxygen anions. Underneath the Co-oxide scale, a thin layer of Re-rich metallic phase with Co-oxide particles exists. (see Fig. 3).

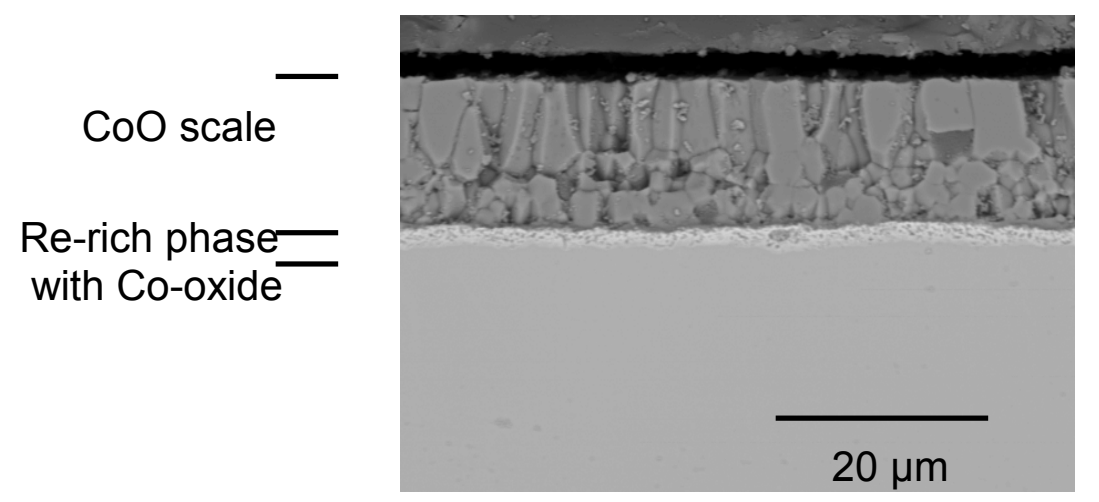

Fig. 3 - Oxide scale on the model alloy Co-17Re after 7 min exposure to laboratory air at $1000^{\circ} \mathrm{C}$

Usually, chromium is added to alloys, e.g., steels or Ni-based alloys, in order to provide corrosion protection through the formation of a slow-growing $\mathrm{Cr}_{2} \mathrm{O}_{3}$ scale on the surface of the substrate. Figure 4 presents oxide scales formed on the quaternary $\mathrm{Co}-17 \mathrm{Re}-\mathrm{xCr}-2.6 \mathrm{C}$ alloys. The oxide scale consist of three layers: an outermost Co-oxide, a porous Co-Cr-oxide and a very thin noncontinuous Cr-oxide layer adhering to the base metal. The oxide scale formed on the alloy Co$17 \mathrm{Re}-30 \mathrm{Cr}-2.6 \mathrm{C}$ is significantly thinner than that one formed on the alloy Co-17Re-23Cr-2.6C. This can be attributed to the formation of more closed $\mathrm{Cr}_{2} \mathrm{O}_{3}$ scale that protects the substrate better from oxidation. It should be noted that the oxidation products of the quaternary alloys studied appear very similar to those of the respective ternary alloys, i.e., without carbon. 


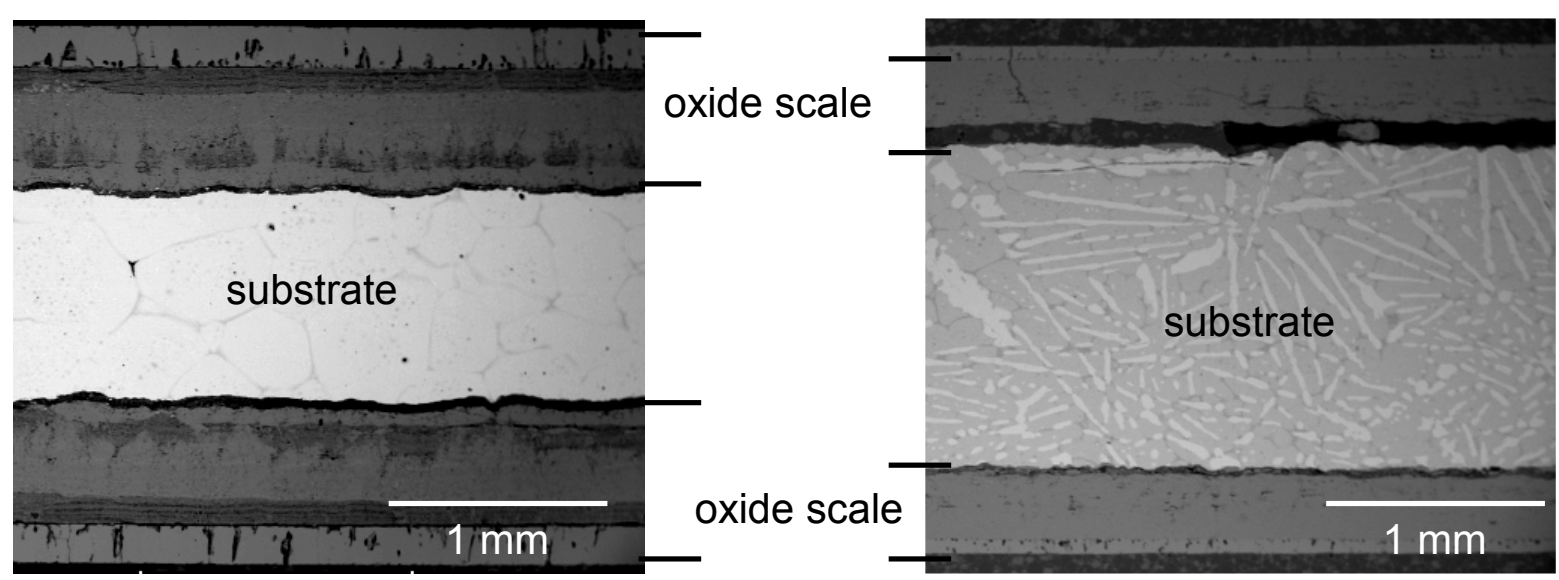

(a)

(b)

Fig. 4 - Cross-section of the quaternary alloys exposed to laboratory air at $1000^{\circ} \mathrm{C}$ for $72 \mathrm{~h}$,

(a) $\mathrm{Co}-17 \mathrm{Re}-23 \mathrm{Cr}-2.6 \mathrm{C}$, (b) $\mathrm{Co}-17 \mathrm{Re}-30 \mathrm{Cr}-2.6 \mathrm{C}$

Figure 5 represents the mass change of the alloys containing $\mathrm{Si}$, which were, identical to alloys presented above, exposed to laboratory air at $1000^{\circ} \mathrm{C}$. The addition of 1 at.\% Si to the ternary alloy Co-17Re-23Cr produced a significant decrease of the mass loss by a factor of about 3 , while increasing the Si-content to 2 and 3 at.\% caused further decreases of the mass loss by a factor of about 1,5 for $\mathrm{Co}-17 \mathrm{Re}-23 \mathrm{Cr}-2 \mathrm{Si}$ and 7,8 for Co-17Re-23Cr-3Si. The oxidation kinetics of the alloy Co-17Re-30Cr-2Si even obeyed the parabolic rate law of the weight gain to a very good approximation (see Fig. 5(b)) indicating the formation of a close and protective oxide scale.

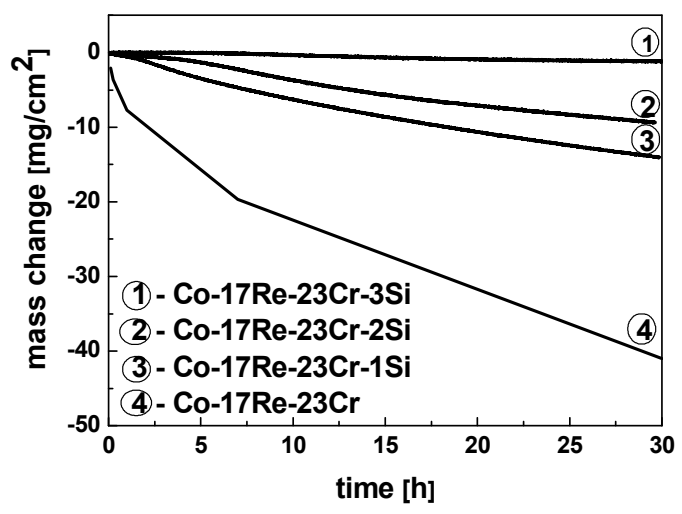

(a)

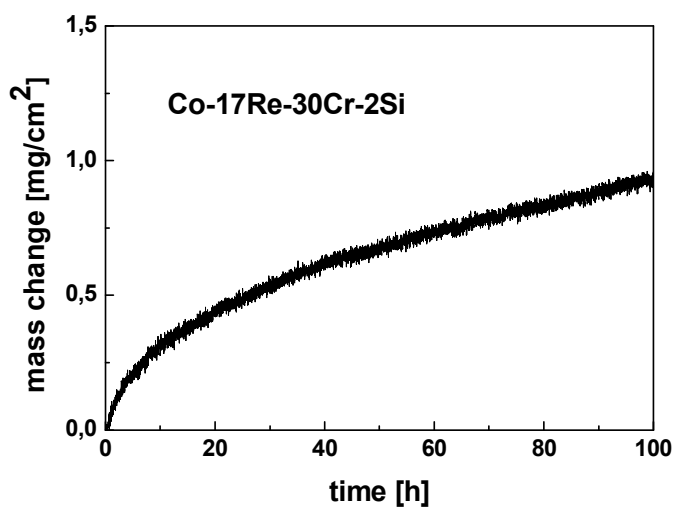

(b)

Fig. 5 - Effect of Si addition on the mass change during oxidation in laboratory air at $1000^{\circ} \mathrm{C}$

Figure 6 shows a cross section of the alloy Co-17Re-30Cr-2Si after exposure to laboratory air for $100 \mathrm{~h}$ at $1000^{\circ} \mathrm{C}$. A continuous, about $8 \mu \mathrm{m}$ thick, compact, and well adherent Cr-oxide layer $\left(\mathrm{Cr}_{2} \mathrm{O}_{3}\right)$ has formed on the surface of the alloy. A zone of internal oxidation of Si-oxide exists underneath the $\mathrm{Cr}_{2} \mathrm{O}_{3}$ outer layer. 


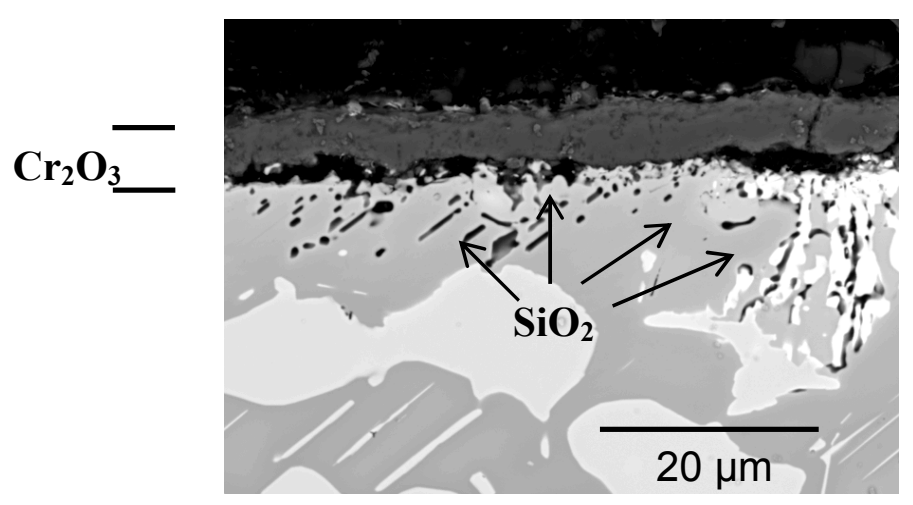

Fig. 6 - Cross-section showing the oxidation behaviour of the model alloy Co-17Re-30Cr-2Si $\left(100 \mathrm{~h}\right.$ of exposure to laboratory air at $\left.1000^{\circ} \mathrm{C}\right)$

\section{Discussion}

Although a mass loss was detected during oxidation of all alloys containing rhenium, thick oxide scales were observed on Co-Re-(xCr)-(2.6C) alloys. Hence, a complex oxidation mechanism takes place during the exposure of these alloys to air at $1000^{\circ} \mathrm{C}$, i.e., oxide scale formation and oxide evaporation occur simultaneously. The oxidation of the binary alloy $\mathrm{Co}-17 \mathrm{Re}$ at $1000^{\circ} \mathrm{C}$ in air yielded a thick $\mathrm{CoO}$ layer with coarse-grained columnar structure (Fig. 3). Numerous investigations on Co-based alloys have shown that $\mathrm{CoO}$ does not provide protective properties at high-temperature [6]. In order to increase the oxidation resistance, $\mathrm{Cr}$ was added to the binary Co-17Re alloy. The oxidation behaviour of the ternary alloys $\mathrm{Co}-17 \mathrm{Re}-\mathrm{xCr}$ with different $\mathrm{Cr}$ amounts, namely $23 \%$ and $30 \%$, possess a similar character. Although these alloys form three different oxides, i.e., $\mathrm{CoO}$, $\mathrm{CoCr}_{2} \mathrm{O}_{4}$ and $\mathrm{Cr}_{2} \mathrm{O}_{3}$, a significant mass loss was detected as a consequence of the evaporation of Re-oxide(s). This agrees to the observation that despite a good adherence of the $\mathrm{Cr}_{2} \mathrm{O}_{3}$ scale, the $\mathrm{Cr}_{2} \mathrm{O}_{3}$ layer is not continuous. It is well-known from the literature that an increase of chromium content in Co-based alloys decreases the oxidation rate reaching a minimum for a $\mathrm{Cr}$ content of $25-$ 30 at. \%, when a single slow-growing $\mathrm{Cr}_{2} \mathrm{O}_{3}$ scale is formed [7]. This is in accordance with the results obtained that an increase of the $\mathrm{Cr}$-content in the ternary alloy $\mathrm{Co}-17 \mathrm{Re}-\mathrm{xCr}$ from $23 \mathrm{at} . \%$ to 30 at.\% reduces the evaporation rate markedly. This effect can be attributed to the formation of a more closed $\mathrm{Cr}_{2} \mathrm{O}_{3}$ scale that protects the base material from rapid oxidation. The addition of $\mathrm{C}$ to the ternary alloy $\mathrm{Co}-17 \mathrm{Re}-\mathrm{xCr}$ was done in order to improve the mechanical properties, particularly the creep behaviour [8]. In general, it was found that carbon does not influence the oxidation behaviour of the Co-Re alloys.

Alloying with silicon can be considered as an encouraging method to improve the oxidation resistance of Co-Re-Cr alloys. The strong positive effect of the Si-addition to the Co-17Re-23Cr alloys was experimentally proven (see Fig. 5(a)). In the alloy Co-17Re-30Cr-2Si silicon addition stabilizes $\mathrm{Cr}_{2} \mathrm{O}_{3}$ scale in such a way that the parabolic mass gain during the exposure to laboratory air was established indicating a formation of a slow growing $\mathrm{Cr}_{2} \mathrm{O}_{3}$ scale. Silica usually forms beneath a chromia scale as internal precipitates or, if the concentration of $\mathrm{Si}$ is high enough and sufficient time elapses, as a more-or-less continuous layer. This layer is important in slowing the rate of chromia scale growth by acting as a partial barrier to diffusion. The transient oxidation of chromia formers is strongly affected by the presence of silicon, which promotes exclusive $\mathrm{Cr}_{2} \mathrm{O}_{3}$ formation [4]. This was observed particularly for Co-based alloys by Durham et. al. [9]. An approximate diffusion analysis showed that bulk alloy properties are not affected by the silicon, and it was concluded that silicon has its effect at the alloy surface by promoting $\mathrm{Cr}_{2} \mathrm{O}_{3}$ nucleation. This explanation seems to held true also for the Co-17Re-xCr-xSi alloys, since a dense and continuous $\mathrm{Cr}_{2} \mathrm{O}_{3}$ scale was observed on the alloy Co-17Re-30Cr-2Si (see Fig. 6). As a perspective, an enhancement of Si-content in the Co-17Re-xCr-xSi to promote the formation of a continuous silica layer is discussed. 
In the case of Mo-Si-B-based alloys, boron is usually added in order to form a continuous borosilica layer $\left(\mathrm{SiO}_{2}\right.$ and $\left.\mathrm{B}_{2} \mathrm{O}_{3}\right)$. This is because boron reduces the viscosity of the glassy silica scale that forms on Mo-Si-B alloys during exposure to air. The low viscosity helps to maintain a continuous protective scale [10]. The $\mathrm{B} / \mathrm{Si}$ ration was found to be very important in adjusting the quality of the silica layer. Lowering the $\mathrm{B} / \mathrm{Si}$ ration results in a decrease of the high-temperature oxidation resistance because silica forms at a slow rate at moderate temperatures [11]. The concept of a formation of an protective borosilica layer will be applied to the Co-Re-Cr alloys.

Another concept to increase the high-temperature oxidation resistance of Co-Re-based alloys is alloying with Al. Many Ni-bade superalloys, the intermetallic $\beta$-NiAl and ferritic FeCrAl alloys are typical alumina formers. These materials have good oxidation resistance due to their ability to form scales which are exclusively $\mathrm{Al}_{2} \mathrm{O}_{3}$ [4]. Oxidation of alumina-forming alloys at temperatures below about $1200^{\circ} \mathrm{C}$ often leads initially to the formation of transient, metastable alumina scales. This is significant, because the metastable aluminas grow much more rapidly than protective $\alpha-\mathrm{Al}_{2} \mathrm{O}_{3}$. Alloying additions such as $\mathrm{Cr}, \mathrm{Pt}$ or $\mathrm{Ni}$ accelerate the transformation from poor protective metastable aluminas to highly stable $\mathrm{Al}_{2} \mathrm{O}_{3}$.

\section{Summary}

In this study the oxidation performance of Co-Re model alloys was reviewed and concepts for the improvement of the oxidation resistance of this class of materials were presented. The previous investigations of this class of Co-Re-Cr alloys showed rather poor oxidation resistance when exposed to laboratory air. Addition of silicon was found to be very promising with respect to the improvement of the oxidation resistance of Co-Re-Cr alloys. Depending on the $\mathrm{Si}$ and $\mathrm{Cr}$ content of the alloy, even a continuous and compact $\mathrm{Cr}_{2} \mathrm{O}_{3}$ can form which suppresses the Re-oxide evaporation. This could be confirmed for the alloy Co-17Re-30Cr-2Si. Other concepts to enhance the oxidation resistance of this class of materials were presented and discussed, such as the formation of a borosilicate layer or protective $\mathrm{Al}_{2} \mathrm{O}_{3}$ scale on the substrate surface.

\section{Acknowledgement}

Financial support of Deutsche Forschungsgemeinschaft (DFG) in the framework of the Research Group "Beyond Ni-Base Superalloys" is gratefully acknowledged.

\section{References}

[1] B.A. Pint, JOM 61, 42 (2009).

[2] V.P. Deodeshmukh and S.K. Srivastava, JOM 61, 56 (2009).

[3] P.C. Patnaik, High Temperature Oxidation and Hot Corrosion of Nickel and Cobalt Based Superalloys, Aeronautical Note NAE-AN-33 NRC No. 25075, Ottawa (1985).

[4] D.J. Young: High Temperature Oxidation and Corrosion of Metals, Elsevier, Oxford (2008).

[5] C.K. Kim, L.W. Hobbs, Oxid. Met. 47, 69 (1997).

[6] P. K. Kofstad and A. Z. Hed, Oxid. Met. 2, 101 (1970).

[7] P. Kofstad: High Temperature Corrosion, Elsevier Applied Science, London (1988).

[8] J. Rösler, D. Mukherji, and T. Baranski, Adv. Eng. Mater. 9, 876 (2007).

[9] R. Durham, B. Gleeson and D.J. Joung, Werkst. Korros. 49, 855 (1998).

[10] J.H. Schneibel, J.J. Kruzic and R.O. Ritchie: Mo-Si-B Alloy Development, information on http://www.ms.ornl.gov/fossil/pdf/APR/FY04/Materials/Schneibel.pdf

[11] F.A. Rioult, S.D. Imhoff, R. Sakidja, J.H. Perepezko: Acta Mat. 57, 4600 (2009). 